\title{
New biological agents in the treatment of multiple sclerosis
}

\author{
Buc M \\ Institute of Immunology, Comenius University Faculty of Medicine, Bratislava, Slovakia. \\ milan.buc@fmed.uniba.sk
}

\begin{abstract}
Multiple sclerosis (MS) is an inflammatory disease induced by autoimmune processes. Their understanding has resulted in an introduction of biological agents to its treatment. Interferon beta and glatiramer acetate have been in clinical practice for more than 20 years. Nowadays, novel biologics, which target molecules involved in immunopathological processes more specifically have entered the scene. They are represented by monoclonal antibodies binding to molecules VLA4 (natalizumab), CD20 (ocrelizumab), CD52 (alemtuzumab) or alpha subunit of IL-2 receptor (daclizumab) or by small molecules such as those modulating the receptors involved in regulation of lymphocyte migration (fingolimod, ozanimod) or in induction of lymphopenia by apoptosis (dimethyl fumarate, cladribine). In the article, we shortly describe their efficacies, adverse reactions and perspectives of a future development in MS biologics. A treatment of neuromyelitis optica by monoclonal antibodies (rituximab, aquaporumab) is given too (Tab. 1, Fig. 2, Ref. 71). Text in PDF www.elis.sk.

KEY WORDS: multiple sclerosis, neuromyelitis optica, monoclonal antibodies, migration of $\mathrm{T}$ and $\mathrm{B}$ cells, JC virus, PML, IRIS.
\end{abstract}

Multiple sclerosis (MS) is an inflammatory disease in which the myelin sheaths around the axons of the brain and spinal cord are damaged, leading to demyelination and scarring as well as to a broad spectrum of signs and symptoms. It is caused by an autoimmune response to self-antigens in a genetically susceptible individual induced by unknown environmental factors (1). Clinical manifestations are heterogeneous depending on the anatomical location of inflammatory lesions. The clinical course is defined either as being relapsing-remitting, which represents around 60 $\%$ of prevalent cases, or progressive (primary if progression starts from the very onset or secondary if it begins after a preceding relapsing-remitting phase). An initial acute episode of neurological disturbance that is suggestive of MS but does not fulfil diagnostic criteria is defined as a clinically isolated syndrome (CIS). Neuromyelitis optica was previously considered to be a variation of MS. Now it represents an independent disease, in which a person's own immune system attacks the optic nerves and spinal cord (2).

The aetiology of MS is still unknown; however, there is strong evidence of an autoimmune pathogenesis sustained by migration of peripheral $\mathrm{T}$ and $\mathrm{B}$ cells into the CNS where they react against myelin or neuronal antigens resulting in induction and maintenance of inflammation. Autoimmune/inflammatory processes cause demyelination, axonal loss, and ultimately neuronal death $(1,3,4)$.

Institute of Immunology, Comenius University Faculty of Medicine, Bratislava, Slovakia

Address for correspondence: M. Buc, MD, DrSc, Institute of Immunology, Comenius University School of Medicine, Odborarske nam 14, SK81372 Batislava, Slovakia.

Phone: +421.2 .59357398$
Current disease-modifying therapies (DMTs) for MS approved by the European Medicine Agency (EMA) and Food and Drug Administration (FDA) in the USA include interferon beta 1a and interferon $1 \mathrm{~b}$, glatiramer acetate, mitoxantrone, natalizumab, fingolimod, teriflunomide, dimethyl fumarate, cladribine, and alemtuzumab. In addition, azathioprine and cyclophosphamide are considered to be off-label drugs or approved in some countries for MS treatment and in some cases also methotrexate and rituximab. All mentioned agents act by modulating the immune system at various levels and with different mechanisms of action.

The aim of this review is to describe the mechanism of action of those biological agents, which have been used in the 2nd and 3rd lines of MS treatment in clinical practice and some of those in clinical trials (emerging MS therapies) (Tab. 1). Generally, available DMTs have a favourable impact on relapsing-remitting MS, while they have no significant benefit in progressive MS.

Natalizumab (NTZ) is a humanised IgG4 monoclonal antibody $(\mathrm{mAb})$, which targets the adhesive molecule VLA4 (alpha 4/beta 1 integrin), its alpha 4 subunit, on membrane of $\mathrm{T}$ cells (Fig. 1). The result is the blockade of VLA4 binding to its partner molecule VCAM1 on the surface of endothelial cells (5). The monoclonal antibodies thus prevent $\mathrm{T}$ cells from sticking to the endothelium and subsequent transmigration to the brain with subsequent attenuation of CNS inflammation. Since 2006, natalizumab has been used for the second line therapy of patients suffering from the relapsing-remitting form of MS (RRMS). It is highly effective and results in a significant decrease in rates of both relapse and disability accumulation, as well as marked decrease in MRI evidence of disease activity $(6,7)$. However, the progressive multifocal leucoencephalopathy (PML) can develop in some patients while its incidence is approximately 1:1,000. PML 
Tab. 1. Mechanisms of action of contemporary and emerging MS therapies.

\begin{tabular}{|c|c|c|}
\hline Drug & Trademark & Mechanism of action \\
\hline IFN- $\beta$ & BETAFERON® & Inhibition of the induction and proliferation of autoreactive $\mathrm{T}$ cells \\
\hline Glatiramer acetate & COPAXONE® & \\
\hline Natalizumab & TYSABRI® & Blockade of transmigration of autoreactive T cells into the CNS \\
\hline $\begin{array}{l}\text { Fingolimod } \\
\text { Ozanimod }\end{array}$ & GILENYA ${ }^{\circledR}$ & Prevention of egress of $\mathrm{CD}^{+} \& \mathrm{CD} 8^{+} \mathrm{T}$ cells, and $\mathrm{B}$ cells from secondary lymphoid tissues \\
\hline Dimethyl fumarate & TECFIDERA ${ }^{\circledR}$ & Lymphopenia caused by depletion of $\mathrm{CD}^{+}$and $\mathrm{CD} 4^{+}$cells + neuroprotective effects \\
\hline Cladribine & LEUSTATIN $®$ & Depletion to B cells, less of T cells \\
\hline Alemtuzumab & LEMTRADA® & Depletion of CD4+\& CD8+ T cells, B cells, NK cells, and monocytes \\
\hline $\begin{array}{l}\text { Rituximab } \\
\text { Ocrelizumab }\end{array}$ & $\begin{array}{l}\text { RITUXAN® } \\
\text { OCREVUS }\end{array}$ & $\begin{array}{l}\text { Depletion of CD20+ B cells and attenuation of antibody independent proinflammatory B cell } \\
\text { functions }\end{array}$ \\
\hline Daclizumab & ZINBRYTA® & Expansion in CD56 ${ }^{\text {bright }} \mathrm{NK}$ cells; inhibition of activated T-cell proliferation \\
\hline
\end{tabular}

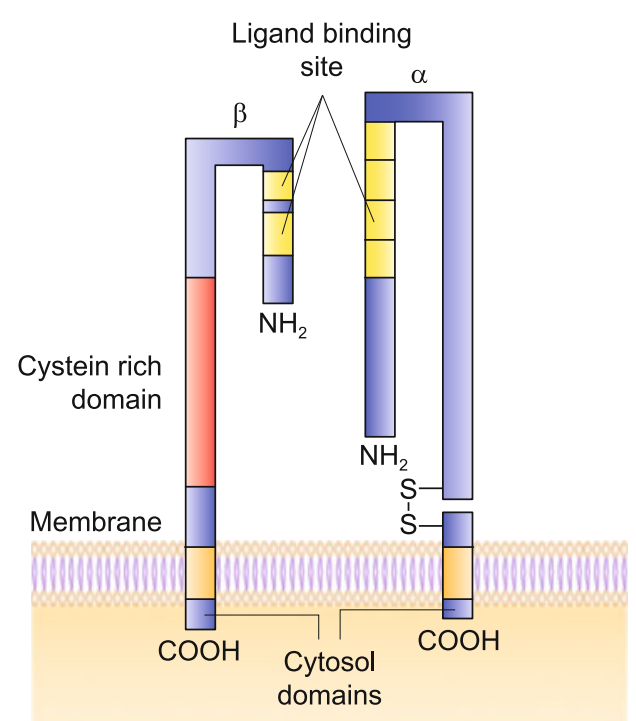

Fig. 1. The biochemical structure of integrins. Integrins are heterodimeric transmembrane molecules consisting of a larger alpha chain and a smaller beta chain. The beta chain within the same integrin family is the same; the alpha chain differs from one member to another, e.g. $\alpha 1 / \beta 1, \alpha 2 / \beta 1, \alpha 3 / \beta 1$ etc. They mediate cell-cell and cell-extracellular matrix interactions.

is a demyelinating disease of CNS due to the polyomavirus John Cunningham (JCV) reactivation; its pathological activity results in oligodendrocytes destruction and can lead to fatal consequences. JCV infection is species-specific and is only found in humans. Primary infection with the virus usually occurs in early life and it is frequently asymptomatic; then JCV presumably remains latent in various tissues $(8,9)$. Patients previously treated by immunosuppressive drugs or those who are treated by NTZ for more than 24 months are more probable to develop this complication (10, 11). Recently, the anti-JCV antibody levels in serum have been identified as a further risk of natalizumab-associated PML (12). In these conditions, discontinuation of NTZ treatment is recommended. After NTZ cessation, the activity of the disease returns to pre-treatment levels. However, some patients can experience severe clinical and radiological worsening - they develop the immune reconstitution inflammatory syndrome (IRIS). It develops some days or weeks after discontinuation of NTZ therapy with
$20 \%$ of mortality. IRIS is characterised by a massive infiltration of lymphocytes to the brain and an intensive immune response to viral antigens and inflammation. Excessive inflammation destroys both, the infected and healthy neurons and glial cells $(13,14)$.

Beside the risk of PML, other circumstances can lead to the decision to stop NTZ therapy, such as incomplete efficacy, tolerability matters, or patient preference for oral therapies. However, the discontinuation can induce a new flare up of the disease in some patients. It is more severe as common relapse seen in patients without previous treatment. The return of disease (the "rebound" phenomenon) probably reflects an increased permeability of the blood-brain barrier with the consequent massive transfer of activated lymphocytes from peripheral blood to CNS. The rebound rate varies among studies between $10 \%$ and $30 \%$ of patients and occurs frequently within the 3-6 months after NTZ withdrawal (15).

Fingolimod (FTY720) is an oral disease-modifying drug for the treatment of RRMS and it is a drug of the second line of therapy. Its first approval was in the USA in 2010, followed by approval in Europe and Japan in 2011.

Fingolimod, a chemical derivative of myriocin from the fungus Isaria sinclairii, shares structural similarities with sphingosine 1-phosphate (S1P). It is a natural phospholipid known to regulate a wide variety of fundamental functions including cell survival, cytoskeletal rearrangements, and cell motility (16). S1P mediates its specific functions by binding to its receptors (S1P1-S1P5). For instance, S1P1 is required in lymphocytes for their egress from the thymus and secondary lymphoid organs, acting by allowing them to respond to the high concentrations of S1P that are present in the blood and other body fluids (17).

Fingolimod becomes phosphorylated by sphingosine kinases, and the phosphorylated form (fingolimod-P) acts as an agonist on 4 of 5 known S1P receptors (all but S1P2) (16). On lymphocytes, fingolimod-P, by binding to S1P1, induces its irreversible internalisation and in this way prevents the egress of activated $\mathrm{T}$ cells from the secondary lymphoid organs. Thus, treatment with fingolimod results in selective and reversible sequestration of $\mathrm{T}$ cells from the blood and spleen into secondary lymphoid organs, thereby preventing the migration of inflammatory cells toward sites of inflammation $(16,18)$.

Naïve $\mathrm{T}$ and $\mathrm{B}$ cells settle in the peripheral lymphoid organs because of their expression of chemokine receptor CCR7. 
The interaction between the chemokine receptor CCR7, expressed on lymphocytes with its cognate ligands CCL19 and CCL21, expressed on high endothelial venules (HEV) is essential for effective migration of T and B cells across HEV into lymph nodes. Central memory $\mathrm{T}$ cells $\left(\mathrm{T}_{\mathrm{CM}}\right)$ express the lymph node homing receptor, CCR7, too (CCR7+CD45RA-). Fingolimod-P prevents the egress of CCR7-positive naïve $\mathrm{T}$ cells and $\mathrm{T}_{\mathrm{CM}}$ cells from lymph nodes. However, it does not block the egress of CCR7-negative effector memory $\mathrm{T}$ cells $\left(\mathrm{T}_{\mathrm{EM}}\right)$, which are a distinct subpopulation of $\mathrm{T}$ cells that are important for immune surveillance $(18,19)$.

$\mathrm{B}$ cells express S1P receptors, and naïve and memory B cells express CCR7 too. The egress of B cells from lymph nodes is S1P1-dependent. Fingolimod reduces the expression of S1P receptors on B cells through receptor internalisation. Therefore, fingolimod may alter the egress of B cells from lymph nodes as well as from the spleen. However, it affects more CD4+ T cells than B cells $(20,21)$.

Fingolimod easily passes through the blood-brain barrier (BBB) where it might modulate the activity of CNS cells. In fact, the recent studies show that fingolimod has direct effects in CNS, and these non-immune mechanisms probably also play a role in preventing the progression of MS (21).

Sphingosine 1-phosphate receptors are expressed over a broad range of tissues (22). Thus, fingolimod might cause adverse effects in a variety of tissues and organs. The most common side effects are headache, fatigue, bradycardia and atrioventricular (AV) block; macular oedema and skin cancer have also been reported $(23,24)$. As mentioned afore, fingolimod does not affect effector memory $\mathrm{T}$ cells $\left(\mathrm{T}_{\mathrm{EM}}\right)$ function the fact of which implies that patients should not suffer from infections. Nevertheless, infections have been reported, including dissemination of herpes zoster virus infection (VZV), herpes simplex virus encephalitis and B cell lymphoma associated with Epstein-Barr virus (EBV) infection $(25,26)$.

Progressive multifocal leucoencephalopathy can develop in some patients treated by fingolimod too, however, its occurrence rate $(1: 10,000)$ is substantially lower compared to that in natalizumab-treated patients (27) (despite extensive use over two decades, there has been no report of PML with either interferon- $\beta$ or glatiramer acetate). Withdrawal of fingolimod treatment can also lead to clinical and radiological worsening similar to that seen after natalizumab cessation because of the development of the immune reconstitution inflammatory syndrome $(28,29)$.

In patients suffering from MS activity despite treatment with IFN- $\beta$ or glatiramer acetate, clinicians often switch therapy to either natalizumab or fingolimod. Some studies, however, suggest that switching to natalizumab is more effective than switching to fingolimod in reducing the relapse rate and short-term disability burden (30).

To bypass adverse effects of fingolimod and to preserve its positive properties, new small molecules were successfully searched for. One of them, ozanimod seems to meet desired expectations. Ozanimod is a novel, oral, selective, small-molecule that targets S1P1 and S1P5. Unlike fingolimod, ozanimod does not need phosphorylation for its activity. Ozanimod has a half-life of 19 hrs, allowing for a once-daily dosing; it causes a dose-dependent decrease in circulating lymphocyte counts, but with rapid lymphocyte recovery after discontinuation of treatment because of its short half-life. Ozanimod was well tolerated in the phase II of clinical trials (31). Researchers recorded no notable cardiovascular, pulmonary, ophthalmic, infectious, or malignancy-related adverse events, including no cases of macular oedema. Based on these positive results, the phase 3 RADIANCE trial began in December 2013; its results will be available next year (31).

Except fingolimod there are other two drugs belonging to orally administered drugs, namely dimethyl fumarate and cladribine.

Dimethyl fumarate (DMF), the methyl ester of fumaric acid, is a new agent that was recently (2013) approved by FDA and EMA for the management of relapsing forms of multiple sclerosis. Being an orally available agent with a favourable safety profile, DMF has become one of the most commonly prescribed disease-modifying agents in the USA and Europe. DMF induces apoptosis of $\mathrm{T}$ cells. It was greater for $\mathrm{CD} 8+$ vs $\mathrm{CD} 4+$, as well as for memory vs naive, and conventional vs regulatory T-cell subsets (32). In addition, DMF influenced dendritic cells by a reduction in their IL-12 and IL-23 synthesis. This attenuation of myeloid antigenpresenting cells in turn reduced the differentiation of CD4+ Th cells into proinflammatory Th1 and Th17 cells, and increased the expression of the Th2 cytokine IL-4 (33). A potential neuroprotective role of DMF has been postulated and is currently thought to be mediated by its action on nuclear factor NRF-2 in astrocytes, oligodendrocytes, and neurons. The binding of NRF-2 to its target genes leads to a transcription of ROS (reactive oxygen species) protective genes (34).

DMF-induced lymphopenia, especially a severe one can result in PML development; however this complication is very rare (35).

Cladribine is a purine analogue (2-chloro-2'-deoxyadenosine) that mimics the nucleoside adenosine. Its metabolites are resistant to deamination by adenosine deaminase and their accumulation results in death of cells (36). Cladribine is activated only by lymphocytes; a non-activated form is removed quickly from all other cells. Nowadays, it has been used as a medication to treat hairy cell leukaemia. However, because of its ability to target preferentially the lymphocytes, it can selectively suppress the immune system too; its administration to patients results in a depletion of $\mathrm{B}$ cells and to a lesser extent it depletes also T cells. It has a positive effect on the treatment of MS patients, like fingolimod, however with fewer adverse effects. The tolerability of oral cladribine in doses tested in MS seems to be very good (37). In June 2017, EMA recommended marketing authorisation for patients with highly active relapsing MS.

Monoclonal antibodies targeting CD52 molecule, alemtuzumab, represents the third line of MS therapy. T and B cells, natural killer (NK) cells, dendritic cells, monocytes, granulocytes express CD52, however not haematopoietic precursors. The biological role of CD52 seems to be in its participation in cell activation, at least in T cells. CD52 cross-linking triggers their activation by inducing similar intracellular tyrosine phosphorylation events as employed by $\mathrm{T}$ cell receptor-mediated signalling. Furthermore, CD52 can serve as a co-stimulatory molecule involved in induction of Treg cells $(38,39)$. 


\section{1-197}

The treatment with alemtuzumab produces a very rapid and almost complete depletion of CD52-bearing cells in circulation, mediated by antibody-dependent cell mediated cytotoxicity (ADCC) $(40,41)$. After depletion, repopulation of immune cells takes place differently. Monocytes return to normal values within three months; B cell counts return to baseline numbers also by three months and are then even increased to about $124 \%$ of pretreatment levels; an enrichment in regulatory B cells accompanies this increase too. T cell counts recover much slower, as the depletion of CD4+ cells lasts a median of 61 months and that of CD8+ cells lasts 30 months. The swift rise of B cells counts may explain a tendency of the alemtuzumab-treated patients to develop some autoimmune disorders. Graves' disease and autoimmune thrombocytopenia belong to the most severe ones $(42,43)$.

The treatment of MS patients with relapsing-remitting forms of the disease with alemtuzumab has significantly reduced the risk of relapse and accumulation of disability. These facts suggested that not only does it reduce the disease activity due to the immune cell-depleting effect, but it also can perform other positive effects. Indeed, it induced the production of neurotrophic factors in autoreactive $\mathrm{T}$ cells providing the CNS with a neuroprotective effect. It was shown that lymphocytes derived from alemtuzumab-treated MS patients produced enhanced amounts of brain-derived neurotrophic factor (BDNF) and ciliary neurotrophic factor (CNTF) upon antigen-specific stimulation with myelin basic protein (MBP) $(44,45)$.

Alemtuzumab possesses a potential risk of PML induction, however no cases of PML have been observed connected with its use till now (27).

Alemtuzumab and natalizumab are highly effective immunotherapies for multiple sclerosis. Both seem to have similar effects on annualised relapse rates in RRMS. Alemtuzumab seems superior to fingolimod in mitigating the relapse activity and natalizumab seems superior to alemtuzumab in enabling recovery from disability (46).

The last decennium has brought the development of new biological agents that can modulate the MS disease processes, and we are now witnessing many trials to verify their modes of action, benefits, and adverse reactions. Among them are novel monoclonal antibodies, especially those targeting CD20 and CD25 molecules.

Anti-CD20 monoclonal antibodies bind to B cells and destroy them by activation of the complement system or killer cells. The rationale behind the decrease in B cells for MS (and other autoimmune disorders) treatment is based on their other biological functions, not only those connected with the production of antibodies. B cells belong to antigen-presenting cells too. They express HLA class II molecules and engulfed protein antigens, previously bound to their immunoglobulin receptors, are then subsequently processed and bound to their grooves. The presentation of the "HLA-molecule - peptide" complex to T cells follows and by receiving costimulatory signals, $\mathrm{T}$ cells are activated $(47,48)$. By the destruction of B cells, anti-CD20 mAb reduce their number and so downregulate their ability to interact with autoreactive $\mathrm{T}$ cells, which results in attenuation of autoimmune processes. Concurrently, a cytokine profile in the microenvironment is changing in support of the induction and expansion of Treg cells (49-51). Why was CD20 molecule selected? The relatively easy answer is as follows: CD20 is expressed on B cell lineage from the pre$\mathrm{B}$ cell to the memory B cell stage, but not on plasma cells (52).

There are three different types of anti-CD20 mAb (they bind to different epitopes of the molecule) used for the treatment of MS, namely rituximab, ofatumumab, and ocrelizumab. Rituximab and ofatumumab destroy B cells by the complement system activation, whereas ocrelizumab by antibody-dependent cell mediated cytotoxicity (ADCC), which is more advantageous as no proinflammatory fragments result from the complement activation. Furthermore, the created apoptotic bodies are immediately engulfed by macrophages, also without any signs of inflammation induction (38).

Rituximab is a chimeric monoclonal antibody. It is used for the treatment of different lymphomas, rheumatoid arthritis (RA) and antineutrophil cytoplasmic antibody (ANCA)-associated vasculitis. In MS, the clinical trials showed good tolerability and a significant reduction in lesions (53). Despite these promising effects, there are no further phase III trials necessary for regulatory approval. Instead, clinical research is focused on newer generation of anti-CD20 mAbs, ocrelizumab and ofatumumab. However, rituximab has still its place in the treatment of neuromyelitis optica. It decreases the attack frequency and severity of the disease; however, it does not remove attacks (54).

Ocrelizumab is a humanised IgG1 antibody with decreased immunogenicity. It binds to a different but overlapping epitopes than rituximab. Ocrelizumab was approved in the USA in March 2017 for the treatment of patients with RRMS or primary progressive MS; currently, it is awaiting its approval for these indications in the European Union. Three pivotal, randomised, multinational phase III trials have demonstrated the efficacy of ocrelizumab in patients with MS. Studies showed better efficiency compared to IFN- $\beta$ 1a. Among ocrelizumab recipients, the most commonly occurring adverse events included upper and lower respiratory tract infections (however, the treatment was not associated with an increased risk of serious infections), infusion-related reactions, skin infections and herpes virus-associated infections. Rarely malignancy, especially breast carcinoma can develop $(53,55)$.

Ofatumumab is a fully humanised anti-CD20 monoclonal antibody. Its binding affinity to CD20 is higher compared to rituximab. It is currently approved for the treatment of chronic lymphatic leukaemia. Concerning MS, two Phase II clinical trials were performed. They showed significant reduction of gadoliniumenhanced lesions. No further details on potential Phase III trials are available yet $(53,56)$.

Daclizumab is a humanised monoclonal antibody that binds to the alpha-chain of IL-2 receptor (CD25), thus effectively blocking the formation of its high-affinity form (Fig. 2). Because the high-affinity IL-2 receptor signalling promotes the expansion of activated $\mathrm{T}$ cells, daclizumab was designed as a therapy that selectively inhibits T-cell activation and received approval as an add-on therapy to a standard immunosuppressive regimen for the prevention of acute allograft rejection in renal transplantation (57). Based on its mechanism of action, daclizumab represented an ideal therapy for $\mathrm{T}$ cell-mediated autoimmune diseases too and 


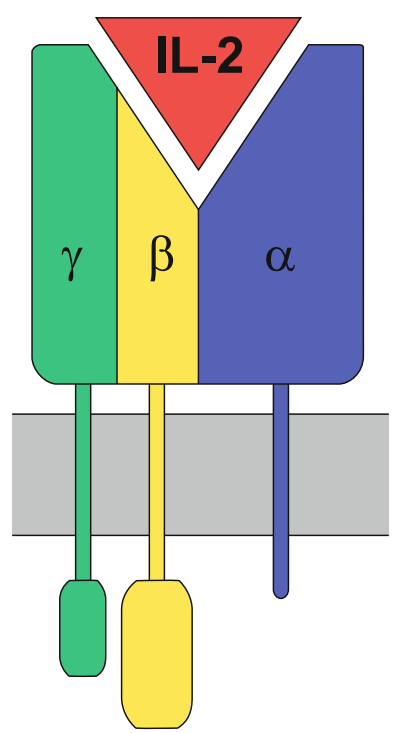

Fig. 2. The biochemical structure of high affinity receptor for interleukin 2 . The IL-2 high affinity receptor is a heterotrimer. T cells express beta and gamma chains in their membranes constitutively; alpha chain joins them only when the $T$ cells become activated.

was subsequently tested in the treatment of inflammatory uveitis and MS. In both of them, it significantly inhibited target organ inflammation. Subsequent studies of mechanisms of its action in MS resulted rather in a surprise; except for an inhibition of T-cell proliferation and production of cytokines, it had expanded and activated immunoregulatory CD56 $6^{\text {bright }} \mathrm{NK}$ cells, which gained access to the brain parenchyma and killed autologous activated T cells (58-60).

The production of original anti-CD25 monoclonal antibodies under the trademark Zenapax was discontinued by 2010 and new ones, called DAC HYP, were developed. They share identical amino acids sequences with the original Zenapax preparations, but a different production process resulted in a different glycosylation pattern of molecules (58). Phases II and III of clinical trials demonstrated that monthly subcutaneous injections of DAC HYP in patients with RRMS led to a significant reduction in annualised relapse rate and decreased the number of gadolinium-enhanced lesions on brain magnetic resonance imaging. The treatment with DAC HYP had efficacy superior to that with weekly injections of INF- $\beta$ 1a. However, the rates of infection, rash, and abnormalities on liver-function testing were higher with DAC HYP than with interferon (61-63). In 2016, FDA and EMA approved DAC HYP for subcutaneous administration for the treatment of patients with MS. Its position in clinical practice is going to evolve over the next few years.

Neuromyelitis optica (NMO) is characterised by selective severe optic nerve and spinal cord inflammation. Previously, NMO used to be considered a specific clinical manifestation of MS; however, since the late 1990s, it is taken as an independent clinical entity. In its immunopathogenesis, autoantibodies targeting aquaporin 4 play a paramount role (64). However, there are pa- tients suffering from similar clinical manifestations and still are anti-AQP4 antibodies negative; instead, they possess autoantibodies targeting myelin oligodendrocyte glycoprotein (MOG) (65). These two overlapping clinical syndromes are now included into the syndrome called neuromyelitis optica spectrum disorder (NMOSD) (66). Aquaporin 4 IgG-associated NMOSD is an immune astrocytopathy with lytic and non-lytic clinical consequences to astrocytes. Conversely, MOG IgG associated NMOSD appears to target myelin and not the astrocytes (67).

The therapy for both AQP4 seropositive and AQP4 seronegative patients must avoid MS-disease-modifying drugs; beta interferons, natalizumab, fingolimod, and alemtuzumab may aggravate NMOSD. Glatiramer-acetate appears to be ineffective. The most commonly used treatments include the oral drugs azathioprine and mycophenolate mofetil (MMF) and intravenous anti-CD20 monoclonal antibody rituximab $(54,66)$.

The better understanding of NMOSD immunopathogenesis has allowed trying other candidate immunotherapies such as eculizumab, a monoclonal antibody that targets $\mathrm{C} 5$ of the terminal component of the complement system activation (68), tocilizumab, an anti-IL-6 receptor monoclonal antibody (69), inebilizumab, an anti-CD19 monoclonal antibody and others (70). Special attention is paid to non-pathogenic monoclonal anti-AQP4 antibody, aquaporumab, which binds to $\mathrm{AQP} 4$, thereby blocking pathogenic autoantibody binding to AQP4 (71). The treatment of NMOSD has not yet been rigorously established on the basis of clinical trials (66), but the future will surely bring the resolution.

The European Medicines Agency recommends an immediate suspension and recall of the daclizumab (ZINBRYTA $®$ ) from the treatment of MS. Its decision is based on 12 reports of serious inflammatory brain disorders worldwide, including encephalitis and meningoencephalitis. Three of those cases led to patient deaths. Moreover, Zinbryta may also be linked to severe immune reactions affecting several other organs (https://www.fiercepharma. com/pharma/ema-suspends-recalls-abbvie-and-biogen-s-doomedms-drug-zinbryta.

\section{References}

1. Sospedra M, Martin R. Immunology of multiple sclerosis. Annu Rev Immunol 2005; 23: 683-747.

2. Lublin FD, Reingold SC, Cohen JA, Cutter GR, Sorensen PS, Thompson AJ et al. Defining the clinical course of multiple sclerosis: the 2013 revisions. Neurology 2014; 83 (3): 278-286.

3. Buc M. Role of regulatory $T$ cells in pathogenesis and biological therapy of multiple sclerosis. Mediators Inflamm 2013; 2013: 963748.

4. Engelhardt B, Ransohoff RM. Capture, crawl, cross: the T cell code to breach the blood-brain barriers. Trends Immunol 2012; 33 (12): 579-859.

5. Elices MJ, Osborn L, Takada Y, Crouse C, Luhowskyj S, Hemler ME et al. VCAM-1 on activated endothelium interacts with the leukocyte integrin VLA-4 at a site distinct from the VLA-4/fibronectin binding site. Cell. 1990; 60 (4): 577-584. 
191-197

6. Polman CH, O'Connor PW, Havrdova E, Hutchinson M, Kappos L, Miller DH et al. A randomized, placebo-controlled trial of natalizumab for relapsing multiple sclerosis. N Engl J Med 2006; 354 (9): 899-910.

7. Miller DH, Khan OA, Sheremata WA, Blumhardt LD, Rice GP, Libonati MA et al. A controlled trial of natalizumab for relapsing multiple sclerosis. N Engl J Med 2003; 348 (1): 15-23.

8. Yousry TA, Major EO, Ryschkewitsch C, Fahle G, Fischer S, Hou $\mathbf{J}$ et al. Evaluation of patients treated with natalizumab for progressive multifocal leukoencephalopathy. N Engl J Med 2006; 354 (9): 924-933.

9. Tan CS, Koralnik IJ. Progressive multifocal leukoencephalopathy and other disorders caused by JC virus: clinical features and pathogenesis. Lancet Neurol 2010; 9 (4): 425-437.

10. Mancini N, Clementi M, Burioni R. Natalizumab-associated progressive multifocal leukoencephalopathy. N Engl J Med 2012; 367 (9): 871-872; author reply 2.

11. Clerico M, Artusi CA, Liberto AD, Rolla S, Bardina V, Barbero $\mathbf{P}$ et al. Natalizumab in Multiple Sclerosis: Long-Term Management. Int J Mol Sci 2017; 18 (5).

12. Plavina T, Subramanyam M, Bloomgren G, Richman S, Pace A, Lee $\mathrm{S}$ et al. Anti-JC virus antibody levels in serum or plasma further define risk of natalizumab-associated progressive multifocal leukoencephalopathy. Ann Neurol 2014; 76 (6): 802-812.

13. Miravalle A, Jensen R, Kinkel RP. Immune reconstitution inflammatory syndrome in patients with multiple sclerosis following cessation of natalizumab therapy. Arch Neurol 2011; 68 (2): 186-191.

14. McGuigan C, Craner M, Guadagno J, Kapoor R, Mazibrada G, Molyneux P et al. Stratification and monitoring of natalizumab-associated progressive multifocal leukoencephalopathy risk: recommendations from an expert group. J Neurol Neurosurg Psychiatry 2016; 87 (2): 117-125.

15. Gonzalez-Suarez I, Rodriguez de Antonio L, Orviz A, MorenoGarcia S, Valle-Arcos MD, Matias-Guiu JA et al. Catastrophic outcome of patients with a rebound after Natalizumab treatment discontinuation. Brain Behav 2017; 7 (4): e00671.

16. Groves A, Kihara Y, Chun J. Fingolimod: direct CNS effects of sphingosine 1-phosphate (S1P) receptor modulation and implications in multiple sclerosis therapy. J Neurol Sci 2013; 328 (1-2): 9-18.

17. Matloubian M, Lo CG, Cinamon G, Lesneski MJ, Xu Y, Brinkmann $\mathbf{V}$ et al. Lymphocyte egress from thymus and peripheral lymphoid organs is dependent on S1P receptor 1. Nature 2004; 427 (6972): $355-360$.

18. Mehling M, Brinkmann V, Antel J, Bar-Or A, Goebels N, Vedrine C et al. FTY720 therapy exerts differential effects on T cell subsets in multiple sclerosis. Neurology 2008; 71 (16): 1261-1267.

19. Sawicka E, Dubois G, Jarai G, Edwards M, Thomas M, Nicholls A et al. The sphingosine 1-phosphate receptor agonist FTY720 differentially affects the sequestration of CD4+/CD25+ T-regulatory cells and enhances their functional activity. J Immunol 2005; 175 (12): 7973-7980.

20. Cinamon G, Matloubian M, Lesneski MJ, Xu Y, Low C, Lu T et al. Sphingosine 1-phosphate receptor 1 promotes $\mathrm{B}$ cell localization in the splenic marginal zone. Nat Immunol 2004; 5 (7): 713-720.

21. Cohen JA, Chun J. Mechanisms of fingolimod's efficacy and adverse effects in multiple sclerosis. Ann Neurol 2011; 69 (5): 759-777.

22. Mutoh T, Rivera R, Chun J. Insights into the pharmacological relevance of lysophospholipid receptors. Br J Pharmacol 2012; 165 (4): 829-844.
23. Forrest M, Sun SY, Hajdu R, Bergstrom J, Card D, Doherty G et al. Immune cell regulation and cardiovascular effects of sphingosine 1-phosphate receptor agonists in rodents are mediated via distinct receptor subtypes. J Pharmacol Exp Ther 2004; 309 (2): 758-768.

24. Jain N, Bhatti MT. Fingolimod-associated macular edema: incidence, detection, and management. Neurology 2012; 78 (9): 672-680.

25. Uccelli A, Ginocchio F, Mancardi GL, Bassetti M. Primary varicella zoster infection associated with fingolimod treatment. Neurology 2011; 76 (11): 1023-1024.

26. Gross CM, Baumgartner A, Rauer S, Stich O. Multiple sclerosis rebound following herpes zoster infection and suspension of fingolimod. Neurology 2012; 79 (19): 2006-2007.

27. Berger JR. Classifying PML risk with disease modifying therapies. Mult Scler Relat Disord 2017; 12: 59-63.

28. Hatcher SE, Waubant E, Graves JS. Rebound Syndrome in Multiple Sclerosis After Fingolimod Cessation-Reply. JAMA Neurol 2016; 73 (11): 1376

29. Gunduz T, Kurtuncu M, Eraksoy M. Severe rebound after withdrawal of fingolimod treatment in patients with multiple sclerosis. Mult Scler Relat Disord 2017; 11: 1-3.

30. Kalincik T, Horakova D, Spelman T, Jokubaitis V, Trojano M, Lugaresi A et al. Switch to natalizumab versus fingolimod in active relapsing-remitting multiple sclerosis. Ann Neurol 2015; 77 (3): 425-435.

31. Cohen JA, Arnold DL, Comi G, Bar-Or A, Gujrathi S, Hartung JP et al. Safety and efficacy of the selective sphingosine 1-phosphate receptor modulator ozanimod in relapsing multiple sclerosis (RADIANCE): a randomised, placebo-controlled, phase 2 trial. Lancet Neurol 2016; 15 (4): 373-381.

32. Ghadiri M, Rezk A, Li R, Evans A, Luessi F, Zipp F et al. Dimethyl fumarate-induced lymphopenia in MS due to differential T-cell subset apoptosis. Neurol Neuroimmunol Neuroinflamm 2017; 4 (3): e340.

33. de Jong R, Bezemer AC, Zomerdijk TP, van de Pouw-Kraan T, Ottenhoff TH, Nibbering PH. Selective stimulation of T helper 2 cytokine responses by the anti-psoriasis agent monomethylfumarate. Eur J Immunol. 1996; 26 (9): 2067-2074.

34. Dubey D, Kieseier BC, Hartung HP, Hemmer B, Warnke C, Menge T et al. Dimethyl fumarate in relapsing-remitting multiple sclerosis: rationale, mechanisms of action, pharmacokinetics, efficacy and safety. Expert Rev Neurother 2015; 15 (4): 339-346.

35. Lehmann-Horn K, Penkert H, Grein P, Leppmeier U, TeuberHanselmann S, Hemmer B et al. PML during dimethyl fumarate treatment of multiple sclerosis: How does lymphopenia matter? Neurology 2016; 87 (4): 440-441.

36. Beutler E. Cladribine (2-chlorodeoxyadenosine). Lancet. 1992; 340 (8825): 952-956.

37. Holmoy T, Torkildsen O, Myhr KM. An update on cladribine for relapsing-remitting multiple sclerosis. Expert Opin Pharmacother 2017.

38. Saidha S, Eckstein C, Calabresi PA. New and emerging disease modifying therapies for multiple sclerosis. Ann N Y Acad Sci 2012; 1247: 117-137.

39. Rowan WC, Hale G, Tite JP, Brett SJ. Cross-linking of the CAMPATH-1 antigen (CD52) triggers activation of normal human T lymphocytes. Int Immunol. 1995; 7 (1): 69-77. 
40. Coles AJ, Cox A, Le Page E, Jones J, Trip SA, Deans J et al. The window of therapeutic opportunity in multiple sclerosis: evidence from monoclonal antibody therapy. J Neurol 2006; 253 (1): 98-108.

41. Investigators CT, Coles AJ, Compston DA, Selmaj KW, Lake SL, Moran S et al. Alemtuzumab vs. interferon beta-1a in early multiple sclerosis. N Engl J Med 2008; 359 (17): 1786-1801.

42. Coles AJ, Wing M, Smith S, Coraddu F, Greer S, Taylor C et al. Pulsed monoclonal antibody treatment and autoimmune thyroid disease in multiple sclerosis. Lancet 1999; 354 (9191): 1691-1695.

43. Thompson SA, Jones JL, Cox AL, Compston DA, Coles AJ. B-cell reconstitution and BAFF after alemtuzumab (Campath-1H) treatment of multiple sclerosis. J Clin Immunol 2010; 30 (1): 99-105.

44. Jones JL, Anderson JM, Phuah CL, Fox EJ, Selmaj K, Margolin D et al. Improvement in disability after alemtuzumab treatment of multiple sclerosis is associated with neuroprotective autoimmunity. Brain 2010; 133 (Pt 8): 2232-2247.

45. Klotz L, Meuth SG, Wiendl H. Immune mechanisms of new therapeutic strategies in multiple sclerosis-A focus on alemtuzumab. Clin Immunol 2012; 142 (1): 25-30.

46. Kalincik T, Brown JWL, Robertson N, Willis M, Scolding N, Rice CM et al. Treatment effectiveness of alemtuzumab compared with natalizumab, fingolimod, and interferon beta in relapsing-remitting multiple sclerosis: a cohort study. Lancet Neurol 2017; 16 (4): 271-281.

47. Buc M. The major histocompatibility complex in man. Folia Biol (Praha). 1995; 41 (3-4): 119-122.

48. Benesova Y, Vasku A, Stourac P, Hladikova M, Fiala A, Bednarik J. Association of HLA-DRB $1 * 1501$ tagging rs3135388 gene polymorphism with multiple sclerosis. J Neuroimmunol 2013; 255 (1-2): 92-96.

49. Barun B, Bar-Or A. Treatment of multiple sclerosis with anti-CD20 antibodies. Clin Immunol 2012; 142 (1): 31-37.

50. Ray A, Basu S, Williams CB, Salzman NH, Dittel BN. A novel IL10 -independent regulatory role for B cells in suppressing autoimmunity by maintenance of regulatory T cells via GITR ligand. J Immunol 2012; 188 (7): 3188-3198.

51. Lund FE, Randall TD. Effector and regulatory B cells: modulators of CD4+ T cell immunity. Nat Rev Immunol 2010; 10 (4): 236-247.

52. Stashenko P, Nadler LM, Hardy R, Schlossman SF. Characterization of a human B lymphocyte-specific antigen. J Immunol. 1980; 125 (4): 1678-1685.

53. Bittner S, Ruck T, Wiendl H, Grauer OM, Meuth SG. Targeting B cells in relapsing-remitting multiple sclerosis: from pathophysiology to optimal clinical management. Ther Adv Neurol Disord 2017; 10 (1): 51-66.

54. Etemadifar M, Salari M, Mirmosayyeb O, Serati M, Nikkhah R, Askari $\mathbf{M}$ et al. Efficacy and safety of rituximab in neuromyelitis optica: Review of evidence. J Res Med Sci 2017; 22: 18.

55. Frampton JE. Ocrelizumab: First Global Approval. Drugs 2017; 77 (9): 1035-1041.

56. Sorensen PS, Lisby S, Grove R, Derosier F, Shackelford S, Havrdova $\mathbf{E}$ et al. Safety and efficacy of ofatumumab in relapsing-remitting multiple sclerosis: a phase 2 study. Neurology 2014; 82 (7): 573-581.
57. Olyaei AJ, Thi K, deMattos AM, Bennett WM. Use of basiliximab and daclizumab in kidney transplantation. Prog Transplant 2001; 11 (1): 33-73; quiz 8-9.

58. Bielekova B. Daclizumab therapy for multiple sclerosis. Neurotherapeutics 2013; 10 (1): 55-67.

59. Bielekova B, Catalfamo M, Reichert-Scrivner S, Packer A, Cerna M, Waldmann TA et al. Regulatory CD56 (bright) natural killer cells mediate immunomodulatory effects of IL-2Ralpha-targeted therapy (daclizumab) in multiple sclerosis. Proc Natl Acad Sci U S A 2006; 103 (15): 5941-5946.

60. Martin R. Anti-CD25 (daclizumab) monoclonal antibody therapy in relapsing-remitting multiple sclerosis. Clin Immunol 2012; 142 (1): 9-14.

61. Preiningerova JL, Vachova M. Daclizumab high-yield process in the treatment of relapsing-remitting multiple sclerosis. Ther Adv Neurol Disord 2017; 10 (1): 67-75.

62. Reynolds D, Duray GZ, Omar R, Soejima K, Neuzil P, Zhang S et al. A Leadless Intracardiac Transcatheter Pacing System. N Engl J Med 2016; 374 (6): 533-541.

63. Kappos L, Wiendl H, Selmaj K, Arnold DL, Havrdova E, Boyko A et al. Daclizumab HYP versus Interferon Beta-1a in Relapsing Multiple Sclerosis. N Engl J Med 2015; 373 (15): 1418-1428.

64. Lennon VA, Wingerchuk DM, Kryzer TJ, Pittock SJ, Lucchinetti CF, Fujihara $\mathbf{K}$ et al. A serum autoantibody marker of neuromyelitis optica: distinction from multiple sclerosis. Lancet 2004; 364 (9451): 2106-2012.

65. Sato DK, Callegaro D, Lana-Peixoto MA, Waters PJ, de Haidar Jorge FM, Takahashi T et al. Distinction between MOG antibody-positive and AQP4 antibody-positive NMO spectrum disorders. Neurology 2014; 82 (6): 474-481.

66. Weinshenker BG, Wingerchuk DM. Neuromyelitis Spectrum Disorders. Mayo Clin Proc 2017; 92 (4): 663-679.

67. Wingerchuk DM, Banwell B, Bennett JL, Cabre P, Carroll W, Chitnis $\mathbf{T}$ et al. International consensus diagnostic criteria for neuromyelitis optica spectrum disorders. Neurology 2015; 85 (2): 177-189.

68. Pittock SJ, Lennon VA, McKeon A, Mandrekar J, Weinshenker BG, Lucchinetti CF et al. Eculizumab in AQP4-IgG-positive relapsing neuromyelitis optica spectrum disorders: an open-label pilot study. Lancet Neurol 2013; 12 (6): 554-562.

69. Araki M, Matsuoka T, Miyamoto K, Kusunoki S, Okamoto T, Murata $\mathbf{M}$ et al. Efficacy of the anti-IL-6 receptor antibody tocilizumab in neuromyelitis optica: a pilot study. Neurology 2014; 82 (15): $1302-1306$

70. Kleiter I, Gold R. Present and Future Therapies in Neuromyelitis Optica Spectrum Disorders. Neurotherapeutics 2016; 13 (1): 70-83.

71. Tradtrantip L, Zhang H, Saadoun S, Phuan PW, Lam C, Papadopoulos MC et al. Anti-aquaporin-4 monoclonal antibody blocker therapy for neuromyelitis optica. Ann Neurol 2012; 71 (3): 314-322.

Received December 16, 2017. Accepted January 3, 2018. 